\title{
Modelling and testing of a load-limiting sandwich structure*
}

\author{
M. Sippola ${ }^{\mathrm{a}}$ and T. Lindroos ${ }^{1}$ \\ Modelling and Simulation of Materials, VTT, P.O. Box 1000, 02044 VTT, Finland \\ ${ }^{1}$ Advanced Materials, VTT, P.O. Box 1000, 02044 VTT, Finland
}

\begin{abstract}
A heavy gust causes a severe load peak to a Wind Turbine (WT) blade. Such load peaks and the consequent vibrations cause fatigue that reduce the lifetime of the blade. The fatigue loads are also a limiting factor in increasing size of WT blades. This paper deals with a load-limiting structure that will not allow the load peak to grow over a chosen limit. The targeted structure is an adaptive airfoil that automatically reduces camber at a heavy gust, which in turn immediately reduces the loads to the blade. This adaptive concept is totally passive, it needs no heating nor control system. The concept is based on an adaptive laminate that contains superelastic Shape Memory Alloy (SMA) wires in one direction, glass fibers in the other direction and a flexible special epoxy matrix. The feasibility of the system is tested by a planar sandwich beam under 3-point bending. The structure is modelled using the ABAQUS finite element program and two different SMA material models: the Aurichhio-Taylor model existing in ABAQUS commercial code and the new iRLOOP UMAT (ASCR-VTT). The modelled results are compared to each other and to experimental results. The results show that the load-limiting concept is feasible, but the tested structure contains too soft matrix and core. It is found that both models work properly for embedded SMA wires and give nearly identical results, but as they can be used for small strains structural models only they are inadequate for modelling smart structures with large geometric or material nonlinearities outside the SMAs themselves. As smart structures often involve many different nonlinearities it is necessary to modify the SMA UMATs for the finite strains cases.
\end{abstract}

\section{Introduction}

The use of wind power is doubling every 2-4 years worldwide. The largest wind turbine in the world at the moment has a rotor diameter over $110 \mathrm{~m}$. There is an interest of doubling or quadrupling the rated power from the present maximum of about $5 \mathrm{MW}$. The required growth in the size of blades is not feasible using the present technologies and materials. Along the growth of the size, the slenderness of wind turbines has increased leading to increased importance of vibration and fatigue control of blades and supporting structures.

This paper presents a potential new way of reducing fatigue of a WT blade. The targeted structure is an adaptive airfoil that automatically reduces camber at a heavy gust, which in turn immediately reduces the loads to the blade. This adaptive concept is totally passive and operates in room temperature, so it consumes no electric power; neither does it need any control system.

The feasibility of the concept was tested by a planar sandwich beam under 3-point bending. The load limiting sandwich structure is based on an adaptive laminate that contains superelastic Shape Memory Alloy (SMA) wires in one direction, glass fibers (GF) in the other direction and a flexible special epoxy matrix. The sandwich has a foam core and the other skin is made of aluminium. The structure was modelled using the ABAQUS finite element program [1] and two different SMA material models: the Aurichhio-Taylor model existing in ABAQUS commercial code [2] and the new iRLOOP model [3] created by P. Sedlak, M. Frost and P. Sittner at ASCR and implemented to ABAQUS at VTT by M. Sippola. The modelled results are compared to each other and to experimental results.

a e-mail: merja.sippola@vtt.fi

This is an Open Access article distributed under the terms of the Creative Commons Attribution-Noncommercial License (http://creativecommons.org/licenses/by-nc/3.0/), which permits unrestricted use, distribution, and reproduction in any noncommercial medium, provided the original work is properly cited. 


\section{Background}

Adaptive and active structures have been shown to have a great potential for creating new solutions for industrial products and processes. First experiments of SMA based composites were made at the end of 1980 at Virginia Tech by Rogers and Robertshaw. After that hybrid composites based on shape memory alloys have emerged as one of the most promising smart material systems and hence they have been a subject of active investigation during the past decade.

In different approaches, shape memory materials have usually been integrated within monolithic or composite host materials to produce components whose functionality or static and dynamic properties could be enhanced or actively tuned in response to environmental changes. Partly due to the technical simplicity of the manufacturing process most of the efforts with embedded shape memory fiber containing composites have been directed to thermoplastic and thermoset polymer matrix composites $[4,5]$.

Generally, shape memory composites can be manufactured with conventional fiber reinforced polymer composite fabrication methods. Many modifications about the basic manufacturing process have been presented in the literature [6-8].

Polymer composites with embedded shape memory materials have been demonstrated in the field including the shape and position control, active and passive control of vibration and acoustic transmission of creep resistant materials subjected to dynamic loads or impact damage in structures.

Vibration damping and acoustic control have been studied by several authors [9-12]. The effectiveness of damping enhancement in polymer composite structures by embedded SMA wires is generally poor, with the exception of the so called guitar string effect when the ends of the beam are fixed. Even though SMAs have a large hysteresis, damping achieved by SMAs embedded into epoxy matrix laminates is usually lower than damping achieved by use of special high-damping polymer matrices only. On the other hand the natural frequency of a load carrying composite beam can be controlled using external wires [13]. This kind of semiactive damping by avoiding frequencies close to resonance has a great potential in lightweight structures.

The studies of SMA based functional composites have revealed the lack of basic knowledge in understanding the SMA material behaviour. Especially the issues concerning the generation of recovery stresses of embedded SMA wires are very important. Designing and manufacturing of adaptive structures requires knowledge about the thermomechanical behaviour of adaptive composites. Despite that only a few studies on recovery stresses and strain recovery of embedded SMAs have been published. Jonnalagadda et al [14] studied the strains in a SMA wire embedded into composite matrix in situ with the Moire method. They found that embedded even in this rather flexible matrix, the transformation in the SMA occurred only near the ends of the beam. This rather surprising result is partially explainable by the fact that the epoxy used had low glass transition temperature. Thus the temperature in these tests was not lifted to the nominal Austenite Finish temperature Af. Still, more transformation throughout the beam was expected. Tsoi et al. [15] showed that the prestrain of SMA wires embedded into composite matrix does not have a straight effect on the generation of recovery stresses. These results can be explained by studying the interaction of the SMA wires and the surrounding laminate and the thermomechanical behaviour of the SMAs. As the volume fraction of the SMA wires is usually small, the elastic stress in the SMAs grows high even in a moderately stiff laminate. Stalmans et al [16] explained what happens inside the embedded SMAs during thermal actuation. Usually in actuator use the SMA has originally been cooled from austenite, resulting in Self Accommodated Martensite (SAM), in which the martensite variants are randomly oriented. In the initial straining (loading to the plateau stress and release of the load) in the martensite phase, part of this SAM has oriented to Preferentially Oriented Martensite (POM), resulting in a pseudoplastic strain (elongation of the wire). Then the wires were embedded during the lamination and the laminate was cured. Now, if the stress in the SMA wires during the actuation grows above the plateau stress, several things happen simultaneously: part of the remaining SAM is transforming to austenite, part of the remaining SAM is orienting to POM and part of the POM is transforming to austenite. The orienting of SAM to POM elongates the wire and thus works opposite to the strain recovery. Only the transformation of POM to austenite leads to shortening of the wire i.e. strain recovery and as the transformation of POM is partially constrained by the matrix, the strain recovery is slow. When the stress in the SMA exceeds the plateau stress, it also shifts the phase transformation temperatures upwards, which means that the wires need to be heated to higher temperature to get full transformation. In many experiments reported in literature this shift of transformation temperatures has not been taken into account and thus the heating has been inadequate. The explanation to the observation that the prestrain of the wires does not have a straight effect on the generation of recovery stresses is that in the embedded SMA only small part of the potential transformation takes place. Increasing the heating gives more transformation, but at a slow rate. This together with very slow cooling of embedded SMA wires makes SMA actuation frequency very low, which reduces the applicability of SMA based active adaptivity in the case of a WT blade. Thus seeking of passive methods becomes necessary.

The interfacial bond of SMA wires with epoxy matrix has been studied by many researchers, for examples [17-19]. In [18] the interfacial bond strength in room temperature between NiTi and epoxy was found 
to be about $600 \mathrm{MPa}$. The interfacial bond can be improved by sandblasting, oxidation or chemical agents. The interfacial bond strength is naturally different with different matrix materials. The epoxy matrices used in [1719] were stiff compared to the one used in the current study. The interfacial bond strength between the soft epoxy and NiTi wire in the current study was not measured.

Several authors, for examples Tsoi et al [20] and Lau et al [21] have studied using embedded superelastic SMA wires in composites for enhancing impact energy absorption. In [20] the SMA wires were embedded in the plane of the laminate, between prepreg FRP layers. The results showed that in some cases some improvement in impact damage can be obtained. In [21] the SMA wires were used as stitches. The results show improvement in impact behaviour. Comparison to GF fiber stitched composites was not shown.

In order to design and optimise the adaptive structure the whole structure including the SMA wires has to be modelled. Unfortunately the general and complex behavior of SMAs (superelasticity, shape memory effect, etc.) has not yet been implemented in commercially available FE programs. Therefore, when a FE analysis is needed to predict the response of shape memory structures or devices, three approaches are available [22]:

(a) using a commercially available software and trying to mimic the behavior of a SMA by a material law already implemented in the program,

(b) implementing a user-programmed material model for a commercial FE software,

or (c) programming both the FE algorithms and the constitutive relation from scratch.

The second approach utilizes commercially available FE software with a user-programmed material law. Rebelo et al. [2] implemented the superelastic model of Auricchio and Taylor [23], including tensioncompression asymmetry, into ABAQUS UMAT. They managed to simulate and validate the superelastic response of complex geometries. The superiority of this superelastic model over the elastic, elasto-plastic and hyperelastic material models was shown by Pease and Walsh [24]. Gong et al. [25] calculated and experimentally validated the radial and resistive forces of a stent with this method. Rebelo et al. [26] moved the development ahead by considering the plasticity of NiTi alloys in their superelastic regime. They validated the loss of properties due to plasticity by a series of experiments performed on a diamond-shaped structure subjected to fatigue. Peultier et al. [27] also implemented a user-defined material model within ABAQUS. They managed to simulate the superelastic response and the shape memory recovery of structures. Also ANSYS has in its material library a superelastic model of SMAs. The model based on the Auricchio algorithm [28] includes tension-compression asymmetry. Barrett and Burpee [29] used this model in ANSYS for the optimization of a stent's performance.

SMA wires have been attempted for thermal actuation of airfoils since the early years of SMA actuation. 2006 Terriault et al [22] used ANSYS for modelling an adaptive miniature airplane wing. In their study the SMA wires were used as external actuator to the laminate inside the wing. Sippola et al [30] studied an adaptive WT blade airfoil with embedded SMA wires (thermal actuation). Contrary to these works the current study uses embedded SMAs as passive adaptation elements utilising the superelasticity phenomenon.

In the current study two different SMA material models were used: 1) the superelastic Auricchio-Taylor SMA material model [2] existing in the commercial code of ABAQUS and 2) the iRLOOP SMA material model [3] created at ASCR by Petr Sedlak, Miroslav Frost and Petr Sittner and implemented to ABAQUS as a User programmed MATerial model (UMAT) at VTT by Merja Sippola.

\section{Structure and test setup}

A schematic picture of the load-limiting sandwich structure is shown in figure 1. The core material used is Airex Foam C70.75 and the passive skin is made of aluminium. The SMA-FRP laminate consists of a special flexible epoxy matrix created at VTT, strengthened by glass fibers in one direction and superelastic SMA wires in another direction. 


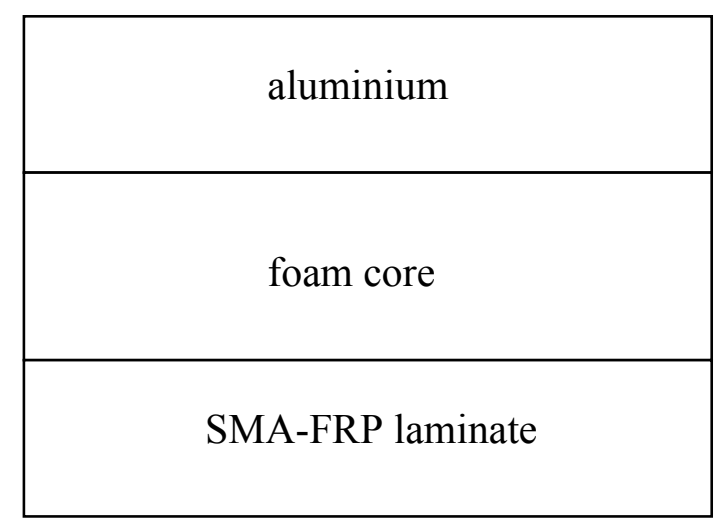

Fig. 1. Schematic picture of the sandwich structure (not in scale).

The basic idea of the structure is that the SMA wires act elastically at service loads, but at a heavy gust the stress in the SMA wires grows high enough to cause phase transformation from austenite to stress-induced martensite. The SMA wire is chosen so that it performs superelastically at room temperature, so no heating is needed. The wires only need to be kept at the temperature range where the superelastic phenomenon occurs. The epoxy matrix is a good thermal insulator. If necessary, other insulating material can be added to the laminate structure. In a real WT blade application, in order to avoid flutter instability, the SMA wire needs to be properly chosen and thermally treated so that there is no level stress plateau, but only a change in the slope of the stressstrain curve, and the superelastic strain needs to be small compared to other applications of superelastic SMA wires. This first test specimen was fabricated with commercial superelastic wire produced by Smart Materials, Beijing. The wire was delivered in 'as drawn' condition with degree of cold work around $30 \%$. The wire was heat treated at $400^{\circ} / 15 \mathrm{~min}$. in air atmosphere and water quenched. This leads to superelastic behaviour in room temperature. A total of $6 \mathrm{SMA}$ wires of diameter $0.49 \mathrm{~mm}$ were used in the 0 -direction. The SMA wires were anchored by Kevlar 29 tows. In the 90-direction 2 layers of UD GF $750 \mathrm{~g} / \mathrm{m} 2$ were used.

The load-limiting sandwich structure was fabricated and the tests were conducted by the Advanced materials group lead by Tomi Lindroos. The structure was tested at a 3 point bending test shown in figure 2 . The test was conducted with universal Instron testing machine in displacement controlled mode $10 \mathrm{~mm} / \mathrm{min}$.

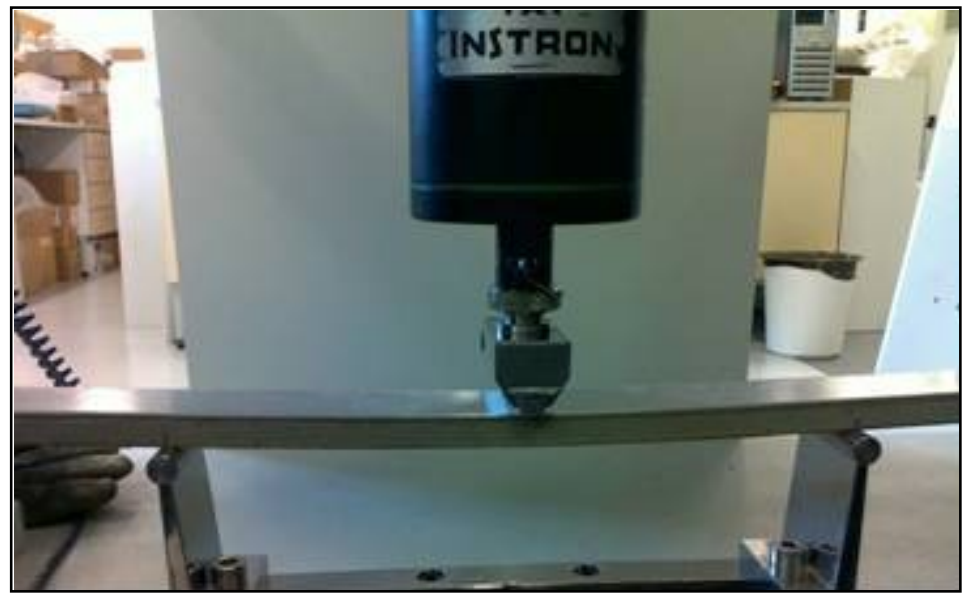

Fig. 2. The 3 point bending test of the load-limiting sandwich structure (beam)

\section{Models and input values}

The ABAQUS model was a 3D shell model, in which the SMA wires were modelled by the *rebar layer option of ABAQUS. A total of 736 S4R elements were used (4-node doubly curved general purpose shell element, reduced integration with hourglass control, finite membrane strains). The *shell section, composite option was used, which allows giving the different material layers separately.

In the model the aluminium, the foam core and the epoxy matrix were considered isotropic. The Young's modulus of the aluminium was $70000 \mathrm{MPa}$ and the Poisson's ratio 0.32. The Young's modulus of the 
foam core was $83 \mathrm{MPa}$ and the Poisson's ratio 0.3833. The Young's modulus of the special epoxy was 95.7 MPa and the Poisson's ratio 0.45. The Young's modulus of the UD glass fibers was $72500 \mathrm{MPa}$ and the Poisson's ratio 0.22. In the 90-direction 2 layers of UD GF $750 \mathrm{~g} / \mathrm{m} 2$ were used. The SMA wires were anchored by Kevlar 29 tows with E $70000 \mathrm{MPa}$ and Poisson's ratio 0.36.

In the model the 90-direction GF layers acted as the host for the 0-direction SMA rebars. The micromechanics equations of Chamis [31] were used for the special epoxy - GF laminate and for the Kevlar tows. The homogenised moduli of the host SMA-GFRP laminate were $\mathrm{E}_{1}$ (orthogonal to SMA) $=29057 \mathrm{MPa}, \mathrm{E}_{2}$ $=\mathrm{E}_{3}=260 \mathrm{MPa}$ and $\mathrm{G}_{12}=\mathrm{G}_{13}=\mathrm{G}_{23}=89 \mathrm{MPa}$, and the Poisson's ratios $\mathrm{v}_{12}=\mathrm{v}_{13}=0.358$ and $\mathrm{v}_{23}=0.449$. The Kevlar tows were also modelled as rebars. The homogenised material values of the Kevlar tows were $\mathrm{E}_{1}=35048$ $\mathrm{MPa}, \mathrm{E}_{2}=\mathrm{E}_{3}=326 \mathrm{MPa}, \mathrm{G}_{12}=\mathrm{G}_{13}=\mathrm{G}_{23}=112 \mathrm{MPa}, \mathrm{v}_{12}=0.405$ and $\mathrm{v}_{23}=0.449$.

For the SMA two different material models were used. 1) the superelastic Auricchio-Taylor [2] SMA material model existing in the commercial code of ABAQUS and 2) the iRLOOP SMA material model [3] created at the Czech Academy of Science (ASCR) by Petr Sedlak, Miroslav Frost and Petr Sittner and implemented to ABAQUS as a User programmed MATerial model (UMAT) at VTT by Merja Sippola.

\section{Results}

For fitting purposes the behaviour of the SMA wire was first modelled using a single T2D2 element (2D truss element) model. Figure 3 shows the stress-strain behaviour of the wire at loading. The experimentally obtained result is shown by solid circles (blue). The solid curve (red) is the one obtained by the Aurichhio-Taylor model and the dashed curve (black) the one obtained by the iRLOOP UMAT. One can see that both models fit to the SMA stress-strain curve very well and give nearly identical stress-strain behaviour in this constant temperature.

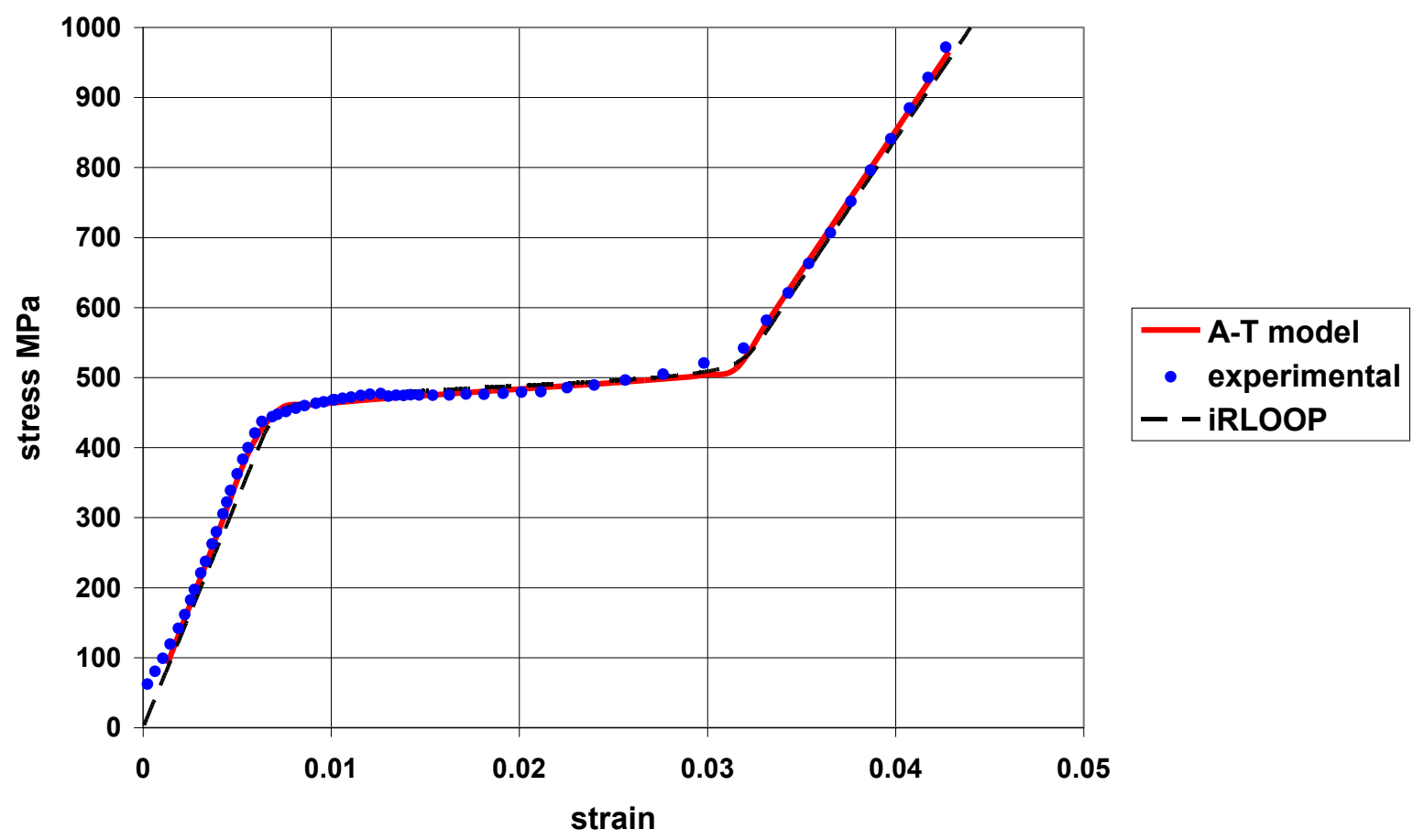

Fig. 3. The experimental and modelled stress-strain curves of the SMA wire

Table 1 shows the values of the parameters used with the Auricchio-Taylor (A-T) model [2] and figure 2 shows the values of the parameters used with the iRLOOP model [3]. The stress parameter values in loading $\left(\sigma_{\mathrm{L}}{ }^{\mathrm{S}}, \sigma_{\mathrm{L}}{ }^{\mathrm{E}}\right)$ for the A-T model obtained from the experiment had to be multiplied by a factor of about 1.3 to get a good fit to the experimental results. The unloading part was not measured. The elastic moduli $\left(\mathrm{E}_{\mathrm{A}}, \mathrm{E}_{\mathrm{M}}\right)$ and the transformation strain $\left(\varepsilon^{\mathrm{L}}\right)$ of the A-T model corresponded well with experimental values. The elastic moduli $\left(\mathrm{E}_{\mathrm{A}}\right.$, $\left.E_{M}\right)$ and the transformation strain $\left(\lambda_{p}\right)$ parameters of iRLOOP model also corresponded well with experimental values. The stress parameter in iRLOOP is the plateau stress in the martensitic state $\left(\sigma_{\text {re }}\right)$, which was not measured. As there was very little information available from the wire, the temperature-related parameters used in the models have assumed values that may not be correct for this particular wire, but as in the current case the temperature is kept constant this is acceptable. In iRLOOP the temperature is scaled so that $\mathrm{A}_{\mathrm{f}}$ is always 0 . 


\begin{tabular}{|r|r|r|r|r|r|r|r|r|}
\hline $\mathrm{E}_{\mathrm{A}}[\mathrm{MPa}]$ & \multicolumn{1}{|c|}{$v_{\mathrm{A}}$} & $\mathrm{E}_{\mathrm{M}}[\mathrm{MPa}]$ & \multicolumn{1}{l|}{$v_{\mathrm{M}}$} & $\varepsilon^{\mathrm{L}}$ & $(\Delta \sigma / \Delta \mathrm{T})_{\mathrm{L}}\left[\mathrm{MPa} /{ }^{\circ} \mathrm{C}\right]$ & $\sigma_{\mathrm{L}}{ }^{\mathrm{S}}[\mathrm{MPa}]$ & $\sigma_{\mathrm{L}}{ }^{\mathrm{E}}[\mathrm{MPa}]$ & $\mathrm{T}_{0}\left[{ }^{\circ} \mathrm{C}\right]$ \\
\hline 70000 & 0.33 & 40000 & 0.33 & 0.0187 & 6.7 & 595 & 660 & 22 \\
\hline
\end{tabular}

\begin{tabular}{|r|r|r|r|r|r|}
\hline$(\Delta \sigma / \Delta \mathrm{T})_{\mathrm{U}}\left[\mathrm{MPa} /{ }^{\circ} \mathrm{C}\right]$ & $\sigma_{\mathrm{U}}^{\mathrm{S}}[\mathrm{MPa}]$ & $\sigma_{\mathrm{U}}^{\mathrm{E}}[\mathrm{MPa}]$ & $\sigma_{\mathrm{CL}}{ }^{\mathrm{S}}[\mathrm{MPa}]$ & $\varepsilon_{\mathrm{V}}{ }^{\mathrm{L}}$ & \multicolumn{1}{l|}{$\mathrm{N}_{\mathrm{A}}$} \\
\hline 6.7 & 420 & 370 & 0 & 0.0187 & 0 \\
\hline
\end{tabular}

Table 1. The parameter values used with the Auricchio-Taylor model

\begin{tabular}{|c|r|r|r|r|r|r|}
\hline $\mathrm{E}_{\mathrm{A}}[\mathrm{MPa}]$ & $\mathrm{E}_{\mathrm{M}}[\mathrm{MPa}]$ & $\sigma_{\mathrm{re}}[\mathrm{MPa}]$ & $\mathrm{s}_{\mathrm{p}}\left[\mathrm{MPa} /{ }^{\circ} \mathrm{C}\right]$ & $\mathrm{S}_{\mathrm{m}}\left[\mathrm{MPa} /{ }^{\circ} \mathrm{C}\right]$ & $\lambda_{\mathrm{p}}$ & $\mathrm{A}_{\mathrm{f}}\left[{ }^{\circ} \mathrm{C}\right]$ \\
\hline 65000 & 40000 & 150 & 7 & 8.5 & 0.019 & 0 \\
\hline
\end{tabular}

\begin{tabular}{|r|r|r|r|r|}
\hline \multicolumn{1}{|c|}{ hysteresis $\left[{ }^{\circ} \mathrm{C}\right]$} & A_M_dynam $\left[{ }^{\circ} \mathrm{C}\right]$ & M_A_dynam $\left[{ }^{\circ} \mathrm{C}\right]$ & $\mathrm{k}$ & $\mathrm{k}_{2}$ \\
\hline 60 & 12 & 30 & 0 & 0 \\
\hline
\end{tabular}

Table 2. The parameter values used with the iRLOOP model

Figure 4 shows the load - midpoint deflection curve of the sandwich beam. Again the experimentally obtained result is shown as solid circles (blue). It can be seen that even though the superelastic plateau of the SMA wire itself (see figure 3) is very level, the slope change in the load-deflection curve of the sandwich is not very sharp. The test was stopped at $17.6 \mathrm{~mm}$ deflection. At that point the phase transformation was not complete and the displacement still grew rapidly compared to load increase.

The solid curve (red) is the one obtained by the Aurichhio-Taylor model and the dashed curve (black) the one obtained by the iRLOOP UMAT. It can be seen that the results obtained by these two models are nearly identical, but the deflection obtained by the models is only about a third of the deflection obtained in the experiment, i.e. the models act a lot stiffer than the experimental specimen. This is caused by the large geometric and material nonlinearities in the test specimen. The change in the slope is at a little higher force in the model than in the experiment.

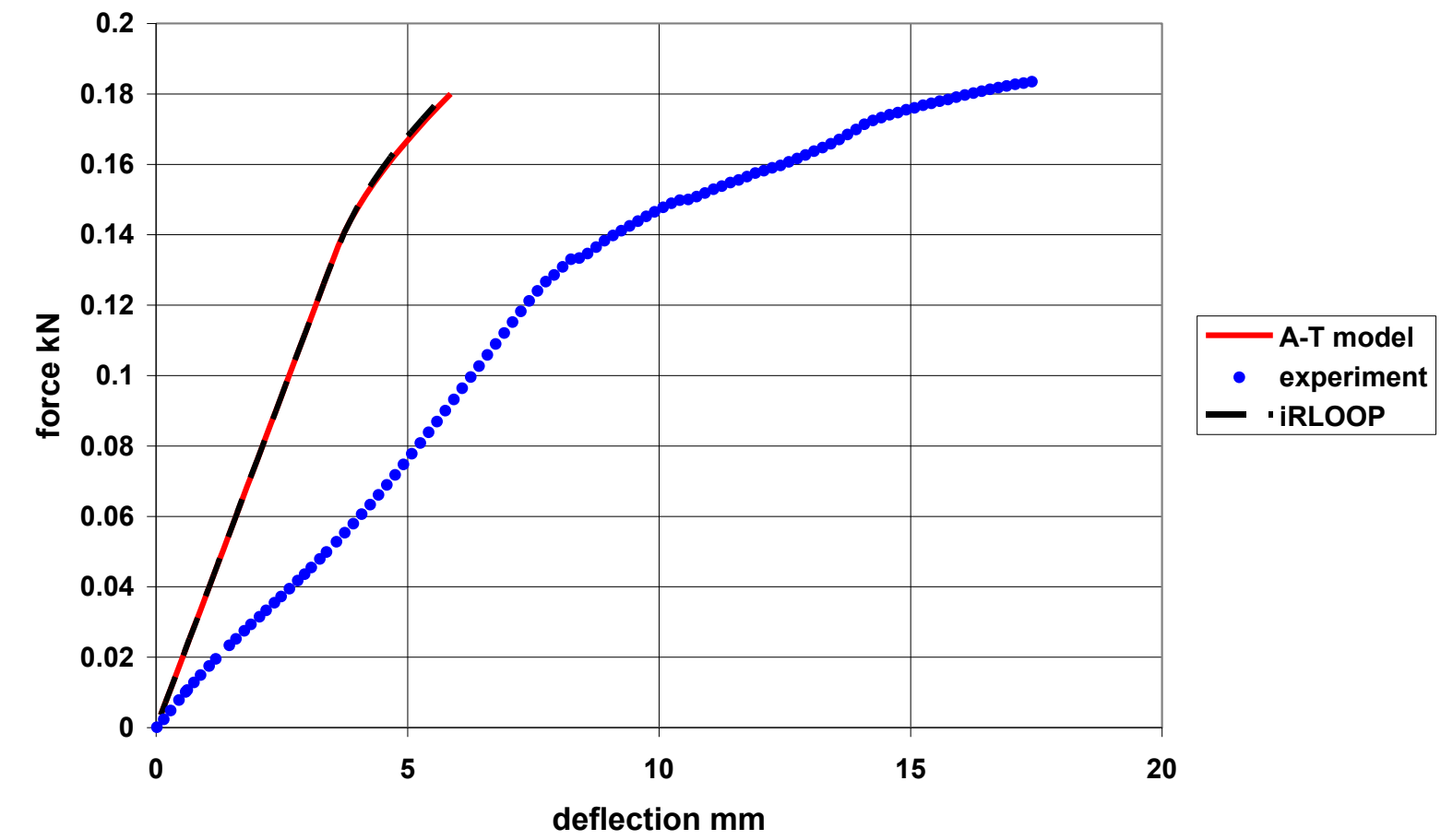

Fig. 4. The experimental and modelled load-deflection curves of the load-limiting sandwich beam

Figure 5 shows the stress-strain curves of the rebars in the ABAQUS models of the load-limiting laminate. The shape is the same as in figure 3. The solid curve (red) is the Auricchio-Taylor model and the dashed curve (black) is the iRLOOP model. 


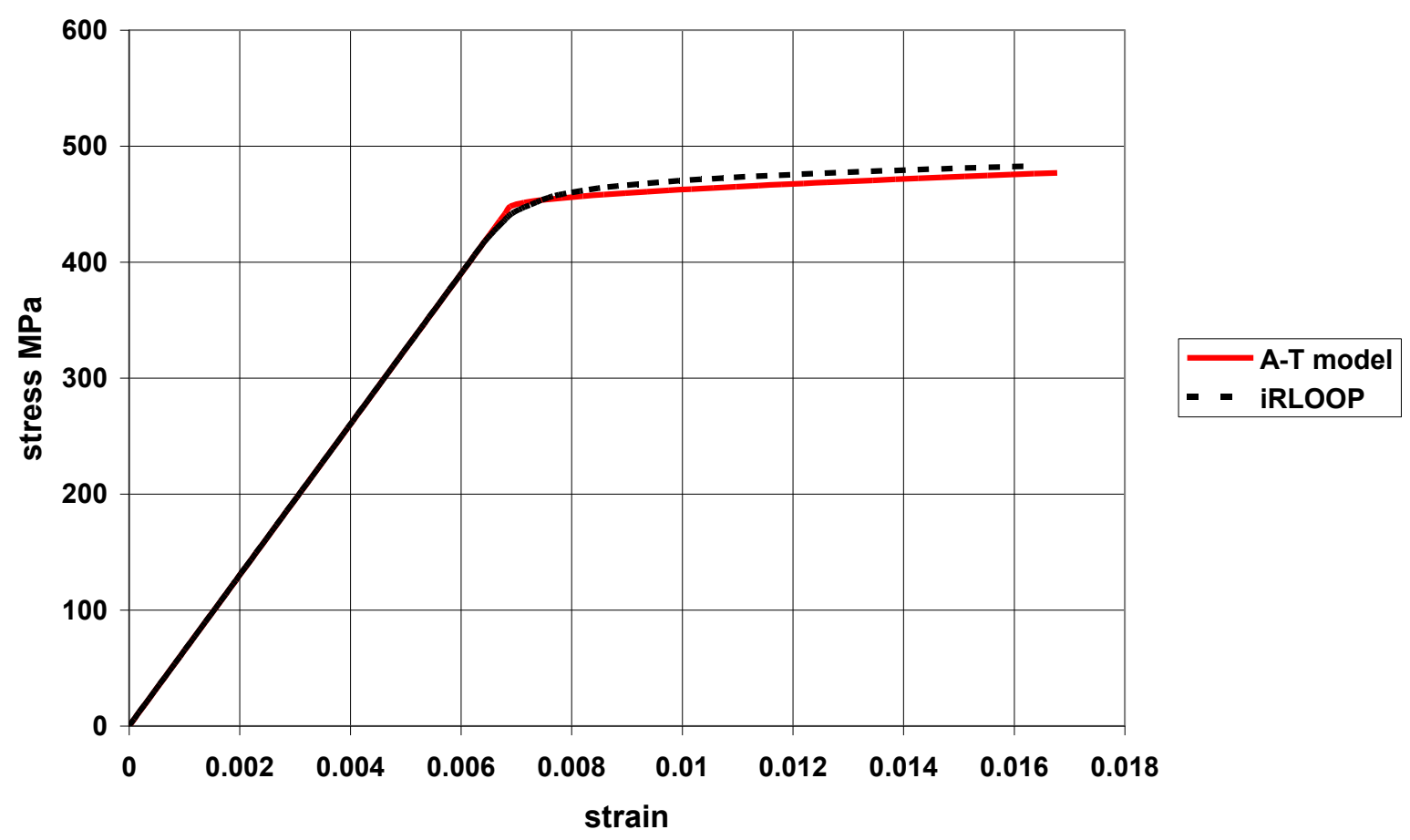

Fig. 5. The stress-strain curves of the rebars in the ABAQUS models of the load-limiting laminate

\section{Discussion}

These results show that the concept of a load-limiting laminate structure using embedded superelastic SMA wires is feasible. This adaptive concept is totally passive, it needs neither heating of the wires nor a control system

The tested structure is far from optimal, though. Due to the large deformation of the too soft core and matrix materials remarkably large deflection of the sandwich is needed to detect superelastic behaviour. Also the integrity of the structure is not good enough for structural use. Furthermore the SMA wires need to be tailored specially for this application. The test was stopped at $17.6 \mathrm{~mm}$ deflection. At that point the phase transformation was not complete and the displacement still grew rapidly compared to load increase. For the real WT blade application, in order to avoid flutter instability, the SMA wire needs to be tailored in order to reduce the superelastic deformation to suitable level for this application, so that the transformation will be complete and the martensite elastic part of the stress-strain curve will be reached before the strains in the matrix and possible extra strengthening fibers grow too large or the camber of the airfoil reduces too much. It would also be beneficial if the superelastic plateau was not very level, so the deformation speed would not rise too high.

Depending on the tailoring results of the SMA wire maybe also other strengthening wires could be used in addition to the SMA wires, provided that the superelastic strain can be made small enough not to break the strengthening wires due to fatigue. Possibly a woven or knitted fabric could be used for strengthening, as the matrix used is so flexible that it will allow some straightening of the fibers even with perfect bonding. The SMA wires also act as strengthening wires in this application. It means that a strong enough bond between the wires and the matrix needs to be ensured and/or the wires must be properly anchored. In this study the SMA wires were anchored by Kevlar tows. The interfacial bond of SMA wires with epoxy matrix can be improved by sandblasting, oxidation or chemical agents. In order to increase the integrity of the structure the SMA wires can also be used as a network, possibly intertwined into a hybrid fabric with glass or aramid fibers. The laminate structure must be such that the temperature in the SMA wires always stays in the range where the wires behave superelastically. Ensuring this may need an extra insulating layer to the outer side of the adaptive laminate, even though the epoxy matrix is a rather good insulator

The large difference in the deflection between the modelled load-limiting sandwich beams and the tested one is caused by the large material and geometric nonlinearities in the test specimen. The matrix and foam core were too soft and deformed too much, especially near the ends of the SMA wires and in the middle, where the SMA wires pushed towards the foam core. In the model the SMA wires were straight whereas in the test specimen it was one SMA wire bent several times to form a zigzagged reinforcement. The very soft matrix allowed the wires to deform a lot at the bends. The model used did not include these nonlinear effects. To 
capture the full behaviour of such a structure the model should be refined, but it is not sensible at this point of the development. In the next version the matrix will be stiffer.

Both UMATs can be used for finite strains (*nlgeom option) in ABAQUS. For finite-membrane-strain elements the material directions rotate with the average rigid body motion of the surface to form the material directions in the current configuration. Stress and strain components in these elements are given relative to these material directions in the current configuration. This gives a fairly good approximation to the small strain assumption.

\section{Conclusion and further work}

The results of this first trial of the load-limiting sandwich structure are promising. With proper tailoring of the materials and structure it seems possible to create a functionable load-limiting airfoil. This adaptive concept is totally passive, it needs neither heating of the SMA wires nor a control system, so it should be easily adapted to real WT blades.

The superelastic Aurichhio-Taylor SMA model in ABAQUS works well in this case. It is relatively easy to fit to experiments. The model is restricted to superelastic case only as it does not contain thermal actuation behaviour of SMAs.

The new ABAQUS UMAT of the SMA model iRLOOP works well for modelling adaptive structures with embedded SMA wires. The iRLOOP UMAT contains also other aspects of SMAs besides superelasticity, especially the thermal actuation behaviour. At present it is not an easy-to-use tool for any structural engineer, but needs rather good understanding of SMAs and FEM from the user. It will be developed towards easier use. Currently its weakest point is the relatively difficult fitting of the parameters to experiments. The development of iRLOOP continues as a co-operation of ASCR and VTT. For example the R-phase transformations of NiTi have been added to the Matlab version of iRLOOP but they have not been implemented to ABAQUS UMAT, yet.

Another version of the load-limiting sandwich beam has been fabricated and tested at VTT after the one reported here. The new version works somewhat better. The next step in this development is the design and optimisation of the adaptive load-limiting airfoil structure. The load-limiting airfoil will then be fabricated and tested for static and gust loads.

This works is part of the UPWIND project funded by the EU and the FORMAFESMA ESF EUROCORES project funded by the Finnish Academy and the ESF. The financial support is gratefully acknowledged.

\section{References}

[1] www.simulia.com

[2] N. Rebelo, M. Hsu, H. Foadian, "Simulation of superelastic alloys behavior with ABAQUS" , Int. Conf. on Shape Memory and Superelastic Technologies (SMST-2000), Pacific Grove, USA, 2001, p. 457

[3] P. Sedlak, M. Frost, M. Landa, P. Sittner, L. Heller, J. Pilch, M. Sippola, "1D model of superelastic and memory NiTi wire", S3T EUROCORES Workshop, Modelling of SMAs and SMA Actuated Structures Workshop, Prague, Czech Republic, May 4-7, 2008

[4] Z.G. Wei, R. Sandström, S. Miyazaki, J. Mater. Sci. Volume 33. (1998), p. 3741

[5] Z.G. Wei, R. Sandström, S. Miyazaki, J. Mater. Sci. Volume 33 (1998), p. 3763

[6] T.L.Turner, C. L. Lach, R. J. Cano, SPIE Volume 4333, Paper No. 4333-60

[7] Y. Xu, K. Otsuka, H. Yoshida, H.Nagai, R. Oishi, H. Horikawa, T. Kishi, Intermetallics Voulume 10 (2000), p. 361

[8] K. Lau, W. Tam, X. Meng, L. Zhou, Materials Letters Volume 57 (2002), p. 364

[9] D. Yang, Z. Wei, Encyclopedia of Smart Materials (John Wiley \& Sons ,2002), p. 551

[10] T.L. Turner, SPIE Volume 3991 Paper No. 3991-47

[11] K. Lau, Materials and design , Volume 23 (2002), p. 741

[12] R.-X. Zhang, N. Qing-Qing, A. Masuda, T. Yamamura, M. Iwamoto, Composite Structures, Volume 74, 2006, p. 389

[13] L. Kantola, P. Söderström, M. Sippola, "Increasing the stiffness of a light weight laminate structure utilising Shape Memory Alloy actuators”, Nordic Vibration Research 2004 conference, KTH Stockholm June 3-4, 2004

[14] K.D. Jonnalagadda, N.R. Sottos, M.A. Qidwai, D. C. Lagoudas, Smart Materials and Structures, Volume 9, 2000, p. 701

[15] K.A. Tsoi, J. Schrooten, Y. Zheng, R. Stalmans, Mater. Sci. Eng. A, Volume 368, 1-2, 2004, p. 299

[16] R. Stalmans, K. Tsoi, J. Schrooten J., Proceedings of SPIE, Volume 4073, 2000, p. 88

[17] K. Jonnalagadda, G.E. Kline, N.R. Sottos, Experimental Mechanics, Volume 37, No 1, 1997, p.78 
[18] C.-K. Poon, K.-T. Lau, L.-M. Zhou, Composites: Part B, Volume 36, 2005, p. 25

[19] N.A. Smith, G.G. Antoun, A.B. Ellis, W.C. Crone, Composites: Part A, Volume 35, 2004, p. 1307

[20] K.A. Tsoi, R. Stalmans, J. Schrooten, M. Wevers, Y.-W. Mai, Mater. Sci. Eng. A, Volume 342, 2003 , p. 207

[21] K.-T. Lau, Smart Mat. Struct., Volume 13, 2004, p. 364

[22] P. Terriault, F. Viens, V. Brailovski, Computat. Mat. Sci.,, Volume 36, 2006, p. 397

[23] F. Auricchio, R.L. Taylor, Computer Methods in Appl. Mech. Eng., Volume 143, 1997, p. 175

[24] M. Pease, B. Walsh, "Nitinol constitutive law comparison for finite-element analysis", Int. Conf. on Shape Memory and Superelastic Technologies (SMST-2000), Pacific Grove, USA, 2001, p. 495

[25] X.G. Gong, A. Pelton, T. Duerig, N. Rebelo, K. Perry, "Finite element analysis and experimental evaluation of superelastic nitinol stent", Int. Conf. on Shape Memory and Superelastic Technologies (SMST-2003),

Pacific Grove, USA, 2003, p. 453

[26] N. Rebelo, X.Y. Gong, M. Conally, "Finite element analysis on plastic behavior in nitinol", Int. Conf. on Shape Memory and Superelastic Technologies (SMST-2003), Pacific Grove, USA, 2003, p. 501

[27] B. Peultier, T. BenZineb, E. Patoor, "Numerical simulation of structures in shape memory alloy", Int. Conf. on Shape Memory and Superelastic Technologies (SMST-2003), Pacific Grove, USA, 2003, p. 489

[28] F. Auricchio, Int. J. of Plasticity, Volume 17, 2001, p. 971

[29] P.R. Barrette, J. Burpee, "Reducing the design cycle of nitinol devices", Int. Conf. on Shape Memory and Superelastic Technologies (SMST-2003), Pacific Grove, USA, 2003, p. 425

[30] M. Sippola, T. Lindroos, T. Brander, J. of Structural Mechanics, Finland, Volume 40, No 1, 2007, p. 65

[31] C.C. Chamis, J. of Compos. Tech. Res., Volume 11, No 1, 1989, p. 3 